\title{
Fourth Ventricle
}

National Cancer Institute

\section{Source}

National Cancer Institute. Fourth Ventricle. NCI Thesaurus. Code C12828.

A diamond-shaped cavity filled with cerebrospinal fluid within the pons extending between the obex in the caudal medulla and the aqueduct of Sylvius in the cerebellum. 